\title{
ЭЛЕКТРОМАГНИТНОЕ ИЗЛУЧЕНИЕ КАК ЗНАЧИМЫЙ ЭКОЛОГИЧЕСКИЙ АСПЕКТ В СЭМ НА ПОДЗЕМНОМ РЕЛЬСОВОМ ТРАНСПОРТЕ
}

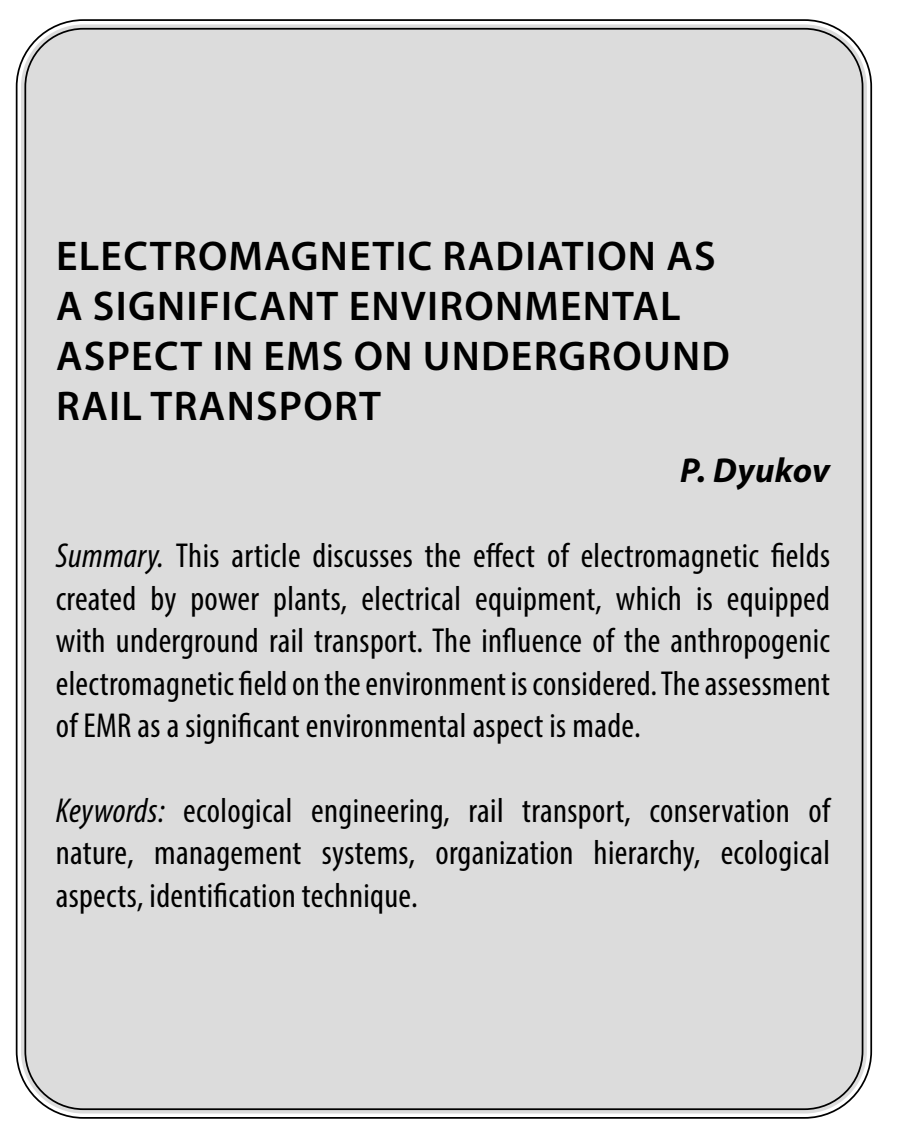

4 елью настоящей статьи является определение электромагнитного излучения как значимого экологического аспекта в системах электроснабжения подземного рельсового транспорта.

Для начала следует отметить, что к подземному рельсовому транспорту относятся такие виды, как метрополитен, подземный скоростной трамвай, подземный фуникулёр, подземная железная дорога в шахтах.

Рельсовые транспортные средства (РТС) предназначены для передвижения по специальным дорогам с особыми направляющими, с которыми образуют особую транспортную систему - железную дорогу

В разных странах исполнение и параметры метрополитенов могут варьироваться (например, бывают почти полностью наземные системы), но отличительными чертами метрополитена являются: использова-
Дюков Пётр Дмитриевич

Российский университет транспорта (РУТ(МИИТ)) dyukov.peter@yandex.ru

Аннотация. В данной статье рассмотрено действие электромагнитных полей, создаваемых силовыми установками, электротехническими средствами, которыми оснащён подземный рельсовый транспорт. Рассмотрено влияние антропогенного электромагнитного поля на окружающую среду. Сделана оценка ЭМИ как значимого экологического аспекта.

Ключевые слова: электромагнитное излучение (ЭМИ); Система экологического менеджмента (СМ); стандарты серии ISO 14000, значимый экологический аспект.

ние электрической тяги, высокая интенсивность и скорость движения поездов и большой пассажиропоток.

В данной статье рассматривается ЭМИ метрополитена, которое отмечается как самая большая величина электромагнитных воздействий на рельсовом транспорте. При отправлении состава величина электромагнитного поля на платформе составляет 50-100 мкТл и более. В самом вагоне при этом отмечается величина магнитной индукции до 150-200 мкТл, т.е. в 10 раз больше, чем в электричке.

Поставленная перед любым метрополитеном мира цель в области охраны окружающей среды и природопользования - повышение уровня экологической безопасности действующих и создаваемых объектов, выражающееся в минимизации негативного воздействия на окружающую среду и обеспечивающее сохранение благоприятной окружающей среды для нынешнего 
и будущих поколений, достигается за счёт планомерного выполнения утверждённой Программы мероприятий, обеспечивающих реализацию положения Экологической политики.

Экологические аспекты хозяйственной деятельности компании требуют принятия экологически ориентированных управленческих решений путем выявления возможных экологических рисков, оценки экологических и экономических последствий экологических рисков, учета общественного мнения, разработки мер по снижению и предотвращению экологических рисков.

Выявление и оценка значимых экологических аспектов, особенно на этапе планирования СЭМ (Система экологического менеджмента), является наиболее фундаментальной частью российского стандарта ГОСТ Р ИСО 14001-2016. Правильное понимание экологических аспектов и их воздействия на окружающую среду является ключом к успеху внедрения стандарта.

Важно отличать экологический аспект от его воздействия.

Согласно, определениям стандарта ГОСТ Р ИСО 14001:2016 можно сделать вывод о том, что изменения в окружающей среде вызываются экологическими аспектами.

«Экологический аспект (environmental aspect): Элемент деятельности организации, её продукции или услуг, который может взаимодействовать с окружающей средой»;

«Окружающая среда (environment): Окружение, в котором функционирует организация, включая воздух, воду, землю, природные ресурсы, флору, фауну, людей и их взаимоотношения»;

«Воздействие на окружающую среду (environmental impact): Любое изменение в окружающей среде отрицательного или положительного характера, полностью или частично являющееся результатом экологических аспектов организации» [1].

Понимание воздействия организации на окружающую среду необходимо для выявления экологических аспектов и определения их значимости. В этой области существует множество подходов, поскольку данный стандарт не содержит ни методов идентификации, ни метода выделения из общего числа значимых аспектов. Для некоторых организаций уже имеющаяся информация о типах воздействий на окружающую среду, связанных с экологическими аспектами, может быть адекватной.
Другие организации могут использовать причинно-следственные диаграммы или блок-схемы для иллюстрации входов и выходов, балансов массы / энергии или использовать другие методы, такие как оценки воздействия на окружающую среду или оценки жизненного цикла.

В соответствии со стандартом, масштаб мер по управлению тем или иным экологическим аспектом должен быть пропорционален характеру риска, который связан с ним. Главное с точки зрения создания эффективной СЭМ, все делать правильно с самого начала. Дотошная и аккуратная идентификация экологических аспектов не только сэкономит время, но и позволит получить огромные преимущества и выгоды.

При составлении реестра необходимо помнить, что с одним и тем же аспектом может быть связано несколько различных видов воздействия, а экологические аспекты различных процессов могут быть одинаковыми по характеру (и отличаться по масштабам, вероятности возникновения и т.п.).

Перечень экологических аспектов должен быть оформлен документально, т.е. является записью СЭМ. В зависимости от групп экологических аспектов в организации может быть разработано несколько реестров: экологических аспектов по выбросам в атмосферу, по сбросам ливневых стоков, по сбросам производственных и бытовых отходов и пр.

Реестр экологических аспектов может меняться не только с изменением деятельности организации и экологического законодательства, но и с изменением знаний об окружающей среде, состояния окружающей среды, национальных приоритетов или приоритетов региона.

Примерами негативных воздействий являются загрязнение воздуха и истощение природных ресурсов.

Примерами положительных воздействий являются улучшение качества воды или почвы.

Взаимосвязь между экологическими аспектами и связанными с ними воздействиями носит причинно-следственный характер. Организации следует знать и понимать те аспекты, которые оказывают или могут оказать значимое воздействие на окружающую среду, т.е. значимые экологические аспекты.

Критерии и методы определения значимых экологических аспектов

Значимость является относительным понятием, её невозможно определить в абсолютных величинах. 
То, что важно для одной организации, может быть несущественным для другой. Оценка значимости требует применения как технического анализа, так и определения отношения организации к конкретному факту. Использование критериев должно помочь организации определить, какие экологические аспекты и связанные с ними воздействия следует считать значимыми.

При использовании критериев значимости организация может установить уровни (или значения) значимости, связанные с каждым из критериев, например, беря за основу сочетание реализуемости (вероятности/ частоты) происходящего события и его последствия (серьёзность/интенсивность). Некоторые виды количественных оценок или ранжирования могут быть использованы при определении значимости, например, числовые или качественные оценки уровня риска, такие как высокий, средний, низкий или пренебрежимо малый.

Так как организация может иметь множество экологических аспектов и связанных с ними воздействий, то следует разработать критерии и методы определения тех из них, которые можно рассматривать как значимые. При разработке критериев следует рассмотреть такие факторы, как характеристики окружающей среды, информацию о законодательных и других требованиях, которые организация обязалась выполнять, а также мнения заинтересованных сторон (внешних и внутренних). Некоторые из этих критериев могут быть применены непосредственно к экологическим аспектам организации, а другие - к связанным с ними воздействиям на окружающую среду.

В соответствии Ф3 «Об охране окружающей среды» все организации РФ должны иметь нормативы предельно допустимых выбросов, сбросов, уровней физических воздействий.

Если фактический уровень воздействия превышает нормативно установленный, то такой экологический аспект должен быть отнесён к категории значимых.

При установлении критериев значимости организации следует рассмотреть следующие вопросы:

а) экологические критерии (такие как масштаб, серьёзность (жёсткость) и продолжительность воздействия или тип, величина и частота проявления экологического аспекта);

б) применимые законодательные требования (такие как предельно допустимые значения выбросов и сбросов, установленные в разрешениях или регламентах и т.п.);

в) мнения внутренних и внешних заинтересованных сторон (такие как мнения относительно ценно- стей организации, имидж в глазах общественности, шум, запахи или видимое ухудшение внешнего облика.

Каждый экологический аспект, который был признан значительным, должен управляться с помощью одного или нескольких механизмов, предусмотренных стандартом: ответственного лица, плана обучения, процедур, контрольных списков или записей, таких как календари технического обслуживания.

Выявление значительных экологических аспектов и связанных с ними воздействий необходимо для определения областей, которые необходимо контролировать или улучшать, и для определения приоритетности действий руководства.

Политика, цели и задачи организации, а также обучение персонала, обмен информацией, операционное управление и программы мониторинга должны быть в первую очередь основаны на знании важных экологических аспектов, но также следует учитывать такие вопросы, как применимое законодательство и другие. требования, которые организация обязалась выполнять, а также мнения заинтересованных сторон.

Идентификация значимых экологических аспектов - постоянный процесс, позволяющий организации лучше понимать своё взаимодействие с окружающей средой и свой вклад в постоянное улучшение экологических характеристик путём совершенствования системы экологического менеджмента.

Особое влияние на окружающую среду оказывают электромагнитные излучения. Это электромагнитное поле, образованное вокруг электрического тока.

Масштабы электромагнитного загрязнения стали настолько значительными, что Всемирная организация здравоохранения (ВО3) включила эту проблему в число наиболее актуальных для человечества. Поэтому в настоящее время во всем мире развернуты обширные исследования, направленные на разработку методов и средств обеспечения экологической безопасности в зонах воздействия ЭМИ.

Электромагнитные поля - это особая форма существования материи, характеризующаяся сочетанием электрических и магнитных свойств.

Физические причины существования переменного электромагнитного поля связаны с тем, что изменяющееся во времени электрическое поле создает магнитное поле, а изменения магнитного поля - вихревое электрическое поле. Сила этих полей, расположенных 
перпендикулярно друг другу, постоянно меняясь, возбуждают друг друга.

Критерием напряженности электрического поля яВляется его напряженность Е с единицей измерения В/м. Критерием напряженности магнитного поля является его напряженность Н с единицей измерения $\mathrm{A} / \mathrm{M}$.

Масштабы электромагнитного загрязнения стали столь существенны, что Всемирная организация здравоохранения (ВО3) включила эту проблему в число наиболее актуальных для человечества. Поэтому в настоящее время во всём мире развёрнуты широкие исследования, направленные на разработку методов и средств обеспечения экологической безопасности в зонах влияния ЭМИ.

Обе составляющие - электрическое и магнитное поля - при непрерывном действии производят взаимное возбуждение, в процессе которого происходит ускорение движущихся частиц. Взаимодействие полей представлено на рис. 2

Формирование электромагнитного поля (ЭМП) в зависимости от расстояния от источника проходит в две стадии. В первом случае электромагнитное поле находится в так называемой зоне индукции и обладает статическими свойствами. Дальнейшее формирование электромагнитного поля с нарастанием интенсивности (скорость заряженных частиц) переводит его в зону электромагнитной волны, в которой формируется излучение.

Основными параметрами источника ЭМП являются частота электромагнитного колебания, измеряемая в герцах (Гц), и длина волны, измеряемая в метрах (м) и скорость распространения.

Тесла - единица измерения плотности магнитного потока, напряжённости и индукции магнитного поля в Международной системе единиц (СИ), названная в честь изобретателя Николы Теслы.

1 тесла равен индукции такого однородного магнитного поля, в котором на 1 метр длины прямого проводника, перпендикулярного вектору магнитной индукции, с током силой 1 ампер действует сила 1 ньютон.

$$
1 \mathrm{~T} л=\frac{\mathrm{H}}{\mathrm{A} * \mathrm{M}}
$$

Их влияние зависит от частоты (U) и длины волны ( $\lambda$ ).

$$
\begin{aligned}
& v=\frac{1}{T}, \text { где } T-\text { период колебания } \\
& \lambda=c \cdot T
\end{aligned}
$$

где $c=3 \cdot 10^{8} \mathrm{~m} / \mathrm{c}-$ скорость света.

Единица измерения электромагнитного излучения (частоты периодических процессов) - Гигагерц (Ггц). Длина волн измеряется в мегаметрах (Мм).

По происхождению выделяют две группы электромагнитных излучений: ЭМИ, связанные с естественными природными источниками, и ЭМИ, связанные с техногенными искусственными источниками.

К естественным относятся составляющие космических, солнечных, атмосферно-климатических процессов, а также процессов, происходящих в глубинных слоях земли при разного рода тектонических движениях. Живые организмы на клеточном уровне либо адаптировались к естественным ЭМИ, либо выработали системы противодействия, исключающие гибель организма.

Основным источником естественных ЭМП на Земле является Солнце.

Техногенные искусственные электромагнитные излучения своим присутствием и постоянным развитием создают динамически растущую добавку к действию естественных ЭМИ, тем самым увеличивая общую опасность для жизнедеятельности.

Все диапазоны техногенных электромагнитных излучений интенсивно влияют на здоровье людей и состояние природной среды. Высокая степень их опасности усугубляется тем, что последствия могут проявляться по истечении достаточно длительного времени и негативно влиять на состояние иммунной и генетической устойчивости поколений. Магнитная составляющая электромагнитного излучения имеет высокую степень опасности для здоровья человека.

Проблема биологического действия электромагнитных полей становится значимой для деятельности международных организаций и государственных органов.

Тезис Всемирной организации здравоохранения: «Не существует уровня облучения, который можно было бы признать абсолютно безопасным». О каком предельно допустимом уровне можно говорить, когда любой уровень если не опасен, то все-таки воздействует на человека и окружающую среду? Различают следующие исходные позиции при нормировании ЭМИ для окружающей среды:

1. Естественный электромагнитный фон. В этом случае ПДУ устанавливается по результатам обобщения имеющихся данных об интенсивности естественного ЭМИ. Искусственные поля не должны 
превышать естественные уровни поля. Очевидно, это положение очень строгое по отношению к излучающим средствам. Случаев создания таких ПДУ ни в России, ни за рубежом не известно, хотя этот подход разрабатывается рядом исследователей. Очевидно, что такой подход интересен только с чисто теоретической точки зрения, поскольку его реализация потребует от человека отказа от технических средств, технологические процессы которых основаны на принципах излучения электромагнитной энергии и даже отказа от использования электроэнергии.

2. Минимальная технически достижимая интенсивность ЭМИ. В качестве ПДУ принимаются существующие мощности ЭМИ некоторых технических средств, от которых, в принципе, не может отказаться человек. Эти ПДУ, как правило, не имеют ни санитарно-гигиенического, ни экологического обоснования.

3. Предельно допустимый санитарно-гигиенический уровень. Такой ПдУ устанавливается человеку по результатам биомедицинских исследований. Введенные таким образом ПдУ для защиты от электромагнитного загрязнения носят санитарно-гигиенический, а не экологический характер. Многие компоненты окружающей среды оказываются более чувствительными к ЭМИ, чем люди, и резко деградируют или исчезают при интенсивном воздействии. Стандартизация ЭМП для людей и информация об электромагнитном загрязнении важны, но все же односторонняя информация для оценки его воздействия. Такие ПДУ нельзя использовать для регулирования ЭМИ в естественных экосистемах.

4. Предельно-допустимый экологический уровень. Устанавливается для окружающей среды по наиболее чувствительным организмам биосферы. Изучение реакций любых биологических компонент экосистем на воздействие любого загрязняющего фактора и разработка на этой основе шкалы оценок вредности воздействия это более совершенный и желательный подход. Такой подход реализуется в системах биоиндикации, которые по электромагнитному фактору пока не созданы.

К низкочастотным электромагнитным излучениям (частота 0-3 кГц) относятся: электротранспорт и его инфраструктура. Транспорт на электроприводе является мощным источником электромагнитных излучений в диапазоне частот от 0 до 100 Гц.

Среди транспортных средств на электрической энергии наибольшие колебания магнитного поля наблюдаются в метро.
Метрополитен представляет собой обособленное сооружение, поэтому вопросы защиты от воздействия электромагнитных полей промышленной частоты и ионизирующих излучений распространяются на находящиеся в нём электроустройств.

Чаще всего линии метро проложены под землёй, в туннелях диаметром около 6 м, и лишь иногда выходят на поверхность или на эстакады. Габариты и масса подвижного состава несколько меньше железнодорожных стандартов, но обычно больше трамвайных Поезд метро состоит из нескольких вагонов: двух головных вагонов (спереди и сзади), имеющих кабины управления, и моторных вагонов между ними. Чаще всего поезда метрополитена насчитывают не более 8 вагонов. Моторы питаются электрическим током, который, как правило, поступает от третьего (контактного) рельса. Каждый поезд метрополитена оснащён надёжной системой автоматического управления. Она не только обеспечивает безопасность, но и регулирует скорость движения по маршруту и останавливает поезд на каждой станции.

Снабжение электроэнергией метрополитена для питания поездов осуществляется от общей энергосистемы города. Переменный ток напряжением 10 кВ преобразуется на тяговых подстанциях метрополитена в постоянный, напряжением 825 В. От «плюсовых» шин тяговых подстанций ток подаётся по кабельной сети, а вдоль линий - по третьему рельсу, являющемуся контактным (KP).

Питание третьего рельса электроэнергией осуществляется при помощи кабелей, идущих от шин постоянного тока тяговых подстанций. Обратными проводами являются ходовые рельсы, от которых электрический ток по кабелям возвращается к шинам тяговых подстанций

Контактный рельс располагают в стороне от ходовых рельсов и несколько выше последних. На обеих сторонах каждого вагона установлено по два токоприёмника, скользящих по третьему рельсу. От токоприёмников электрическая энергия подводится к электродвигателям, называемым тяговыми. Ток отводится к «минусовым» шинам тяговых подстанций через ходовые рельсы. Подстанции располагают вдоль линии на расстоянии нескольких километров одна от другой.

К устройствам освещения, автоблокировки, водоотливным устройствам, вентиляторам и прочим обустройствам метрополитена электроэнергия подаётся от понизительных подстанций, трансформаторы которых понижают подводимое напряжение до требуемого значения. 
Электрическая часть вагона, кроме тяговых двигателей, содержит множество различных аппаратов, предназначенных для пуска тяговых двигателей, изменения скорости и направления движения вагона, электрического торможения, защиты оборудования от перегрузок и токов короткого замыкания, а также аппараты вспомогательных цепей и цепей управления.

Источником ЭМП в электропоездах метрополитена являются тяговые двигатели, пускотормозящие сопротивления, групповые переключатели, кабели токоприёмника, токонесущий провод.

Значительные УНч (ультронизкие частоты) вариации ЭМП наблюдаются в кабинах машинистов метрополитена в горизонтальной Y- компоненте (перпендикулярно рельсам), где значение от «пика до пика» достигают 425 мкТл (при норме 0,2-0,3 мкТл). в кабине машиниста вагона.

Таким образом ЭМП в 7-14 раз превосходит величину естественного постоянного поля Земли (от 25 до 50 мкТл). В пассажирских вагонах поле варьируется в пределах 75-300 мкТл.

При отправлении состава величина магнитного поля на платформе составляет 50-100 мкТл и больше (при норме 0,2-0,3 мкТл). И даже когда поезд давно исчезал в тоннеле, магнитное поле никак не желало вернуться к прежнему значению. Лишь после того, как состав проходил следующую точку подключения к контактному рельсу или шёл накатом, магнитное поле на платформе возвращалось к старому значению.

В самом вагоне метро магнитное поле ещё выше 150-200 мкТл, то есть в 10 раз выше, чем в обычной наземной электричке и в сто раз выше нормы 0,2-0,3 мкТл.

Соответственно, электромагнитное излучение в метрополитене значимый экологический аспект.

В заключение, можно сказать, что ЭМП в поездах метрополитена и на платформах неоднородно по пространству и являются мультичастотными полями, которые быстро меняются во времени и пространстве. Эти черты ЭМП являются следствием суммирования многообразных источников МП в электропоездах и меняющихся режимов движения.

Все источники электромагнитного излучения в условиях туннелей метро наслаиваются друг на друга и создают эффект, схожий с работой СВЧ-печи. Пиковый фон наблюдается в момент разгона поезда и движения по туннелю, а минимальный во время высадки и посадки пассажиров на станциях.

С приходом мобильной связи непосредственно в тоннели метрополитена, электромагнитная опасность этого вида транспорта возросла в разы.

Помимо линий электроснабжения, магнитные поля внутри электротранспорта создаются также внутренней системой питания необходимой для организации освещения, отопления и кондиционирования. Эти системы питаются через кабель, обычно протянутый под составом.

В результате магнитные поля могут заметно различаться в разных частях вагона - в нижней части оно выше. Если же речь идёт о поезде, то сила магнитного поля может различаться от вагона к вагону - ближе к локомотиву оно выше. Кроме того, магнитные поля генерируются разным движущимися компонентами состава. В результате уровень поля в пределах состава может гулять в очень большом диапазоне, причём рост приходится на разгон и торможение.

Поэтому неудивительно, что приводимые в разных исследованиях данные имеют значительный разброс. Для определения корректных усреднённых значений нужна очень большая статистика, и показатели в каждой конкретной поездке могут сильно отличаться от среднего значения.

Отсюда следует, что идентификация значимых экологических аспектов и связанных с ними воздействий электромагнитного излучения необходима для определения тех областей, которые необходимо контролировать или улучшить, а также для установления приоритетов в действиях руководства метрополитенов во всём мире.

Особенностью современного этапа регулирования электромагнитного воздействия как фактора загрязнения окружающей среды является отсутствие механизма экономической защиты, выражающегося принципом «загрязнитель платит». В мировой практике общественных отношений именно этот принцип обеспечивает экологизацию социально-экономического развития общества. На сегодняшний день в России не сформирован эффективно действующий экономический механизм, позволяющий снижать и компенсировать ущерб, наносимый ЭМИ окружающей среде. В отношении загрязнителей окружающей среды электромагнитными полями (ЭМП) в настоящее время не реализуются положения Закона «Об охране окружающей среды» и ряда подзаконных актов, утверждающих принцип платности за использование природных ресурсов и нанесение ущерба здоровью, людей и окружающей среде. 


\section{ЛИТЕРАТУРА}

1. ГоСТ Р ИСО 14001: 2016. Система экологического менеджмента. Требование и руководство по применению.

2. Федеральный закон «06 охране окружающей среды» М., 2002

3. Демьяненко А.Ф. Идентификация экоаспектов в иерархических структурах. /Москва, Мир транспорта № 62012 г.

4. Закиев Е.Э. Опасные электромагнитные поля на подвижном составе и в локомативных депо электрофицированных железных дорог. Диссертация на сосик. Учёной степени кандидат технических наук. Москва, 2007

5. СанПиН 2.2.4.723-98 Переменные магнитные поля промышленной частоты (50 Гц) в производственных условиях.

6. Горский, А.Н. Электромагнитные излучения и защита от них: учебное пособие /А.Н. Горский, Л.К. Васильева; Петербургский государственный университет путей сообщения. СПб. 2000.

7. Свижевский В.А., Стовбур Н.Н. Современные проблемы гигиенического нормирования физических факторов, воздействующих на персонал и пассажиров метрополитена // Бюллетень ВСНЦ СО РАМН».— Иркутск, 2011. — № 1(77).

8. Мельниченко П.И., Свижевский В.А., Стовбур Н.Н. Матвеев А.А Гигиеническое нормирование физических факторов в метрополитене // Медицинское право.— М.: 2011.— № 35 (39).

9. Яременко А.В. Методические подходы к обоснованию платы за негативное воздействие физических факторов на состояние окружающей среды на примере электромагнитных воздействий // Теория и практика экологического страхования: региональный фактор. Труды IX Всероссийской и IV Международной конференций. М.: НИЦ «Экопроект», 2009.

() Дюков Пётр Дмитриевич ( dyukov.peter@yandex.ru)

Журнал «Современная наука: актуальные проблемы теории и практики»

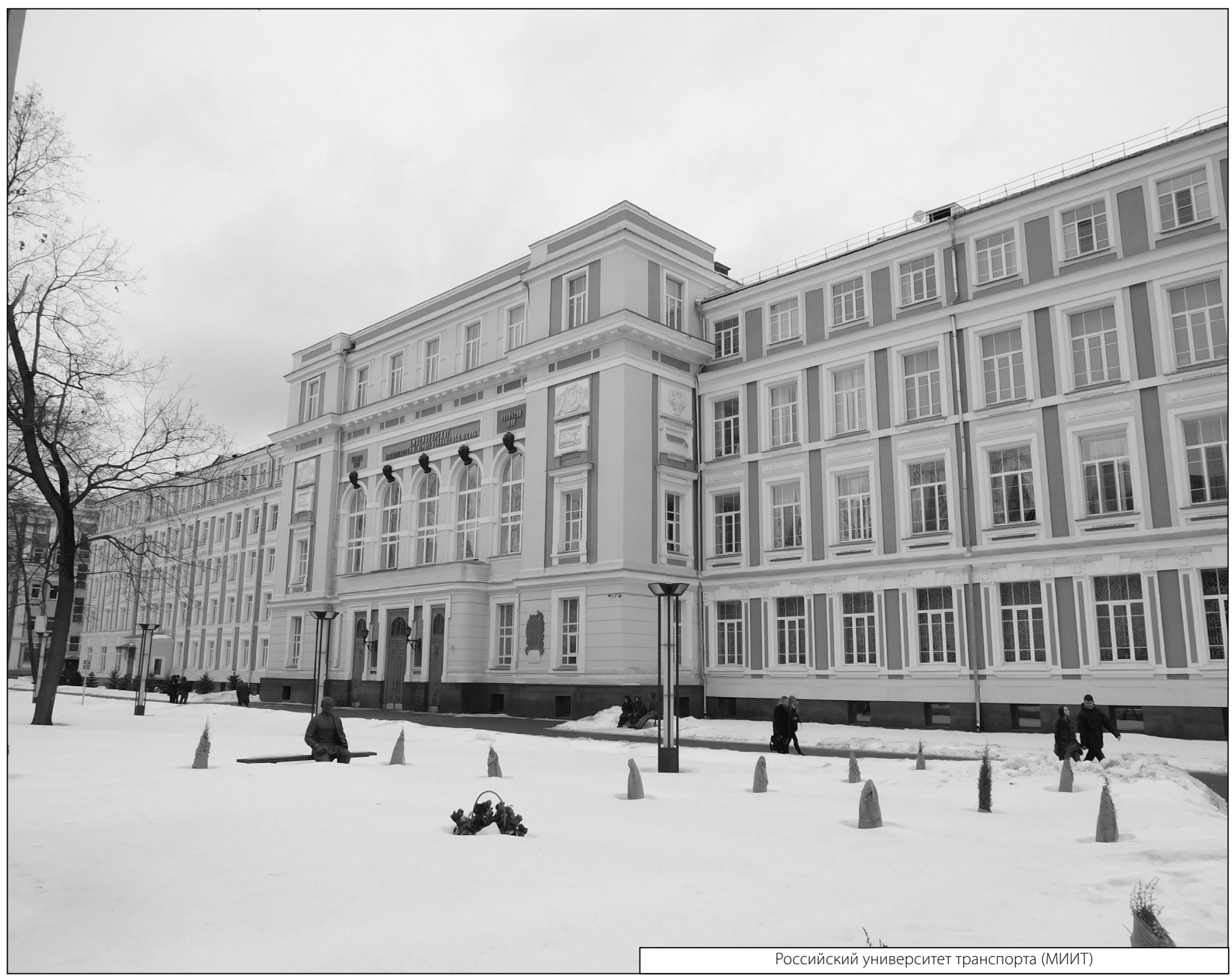

